\title{
SISTEM PENGOLAHAN DATA PESERTA DIDIK PADA LKP PRIMA TAMA KOMPUTER DUMAI DENGAN MENGGUNAKAN BAHASA PEMROGRAMAN PHP
}

\author{
Rahmad Kurniawan ${ }^{1}$, Septedian Marhamelda ${ }^{2}$ \\ ${ }^{1,2}$ Sekolah Tinggi Manajemen Informatika dan Komputer (STMIK) Dumai \\ Jalan Bukit Batrem Kota Dumai kode pos 28811 \\ e-mail : rahmad0412@gmail.com
}

\begin{abstract}
ABSTRAK
LKP Prima Tama Komputer Dumai merupakan lembaga kursus dan pelatihan komputer. Pengolahan data masih menggunakan Microsoft Excel dan Microsoft Word, dalam pencarian data memerlukan waktu yang lama dan sering terjadi redudansi data. Dari masalah tersebut maka dibuatlah sebuah aplikasi dengan menggunakan bahasa pemograman PHP dan Database sebagai tempat penyimpanan data. Dengan adanya aplikasi ini maka data hanya sekali input langsung tersimpan kedalam database dan tidak ada data yang ganda karena mempunyai primary key yang berbeda. Untuk pencarian data tidak memerlukan waktu yang lama cukup dengan membuka form pencarian. Dan membuat sertifikat pesreta didik menjadi cepatdan mudah.
\end{abstract}

Kata kunci : Pengolahan Data, Sistem, Peserta Didik, client server, PHP.

\section{ABSTRACT}

LKP Prima Tama Komputer Dumai is a computer training and course institution. Data processing still uses Microsoft Excel and Microsoft Word, in data searching it takes a long time and data redundancy often occurs. From these problems, an application was made using the PHP programming language and database as a data storage area. With this application, the data is only once input directly stored in the database and there is no double data because it has a different primary key. To search data does not require a long time just by opening the search form. And making pesreta certificates becomes fast and easy.

Keywords: Data Processing, client servers, Systems, Students, $P H P$.

\section{PENDAHULUAN}

LKP Prima Tama Komputer Dumai adalah salah satu lembaga kursus dan pelatihan computer untuk mempersiapkan dan meningkatkan keahlian sumber daya alam manusia yang sesuai dengan tuntutan dunia kerja. Selain itu LKP Prima Tama Komputer Dumai juga sebagai wadah bagi pengembangan ilmu pengetahuan terapan yang praktis dan terpadu yang mengacu pada pengembangan wawasan dan keterampilan praktisi. Jumlah peserta didik yang ada pada LKP Prima Tama Komputer Dumai sampai saat ini telah mencapai 660 peserta didik. Peserta didik yang telah mengikuti pembelajaran dengan baik dapat meemperolah sertifikat.
Pada LKP Prima Tama Komputer Dumai proses pengolahan peserta didik menjadi salah satu kegiatan utama, karena dengan proses pengolahan data ini dapat diketahui tentang program keahlian yang diambil serta nilai peserta didik tersebut. Proses pada LKP Prima Tama Komputer Dumai di mulai dari pengolahan peserta didik hingga menghasilkan sertifikat masih dilakukan secara manual yaitu menggunakan Microsoft Excel, seperti pengolahan peserta didik, instruktur, program keahlian, detail program keahlian, kelas, user, pimpinan, pengajaran, absen, nilai serta dalam mencetak sertifikat. Dan pada pembuatan laporan masih berupa arsip pembukuan. Selain itu juga kesulitan mencari data yang diperlukan jika dalam waktu yang cepat karena harus 
mencari satu-persatu sehingga memungkinkan waktu yang digunakan kurang efektif dan efisien.

Oleh karena itu perlu ada sebuah sistem pengolahan data akan diupayakan dapat dioperasikan melalui sistem menggunakan pemrograman PHP, yang dapat memudahkan kegiatan yang ada pada LKP Prima Tama Komputer Dumai. Selain itu dengan adanya sistem tersebut dapat memberikan suata data lebih efektif dan efisien sesuai dengan yang dibutuhkan oleh pihak LKP Prima Tama Komputer Dumai.

\section{a. Pengertian Sistem}

Sistem adalah sekelompok elemen yang saling berhubungan atau berinteraksi hingga membentuk satu persatuan. Konsep umum system adalah sekelompok komponen yang saling berhubungan, bekerjasama untuk mencapai tujuan bersama dengan menerima input serta menghasilkan output dalam proses transformasi yang teratur. (Indrajani, 2015)

Sistem adalah kumpulan dari elemenelemen yang berinteraksi untuk mencapai suatu tujuan tertentu. Pendekatan sistem yang merupakan kumpulan dari elemen-elemen atau komponen-komponen atau subsitem-subsistem merupakan definisi yang lebih luas. Definisi ini lebih banyak diterima, karena kenyataannya suatu sistem data terdiri dari beberapa subsistem atau sistem-sistem bagia. (Yunita, 2018)

\section{b. Pengertian Data}

Istilah data adalah suatu istilah majemuk yang berarti fakta atau bagian dari fakta yang mengandung arti yang dihubungkan dengan kenyataan, simbol-simbol, gambar-gambar, angka-angka, huruf-huruf atau simbol-simbol yang menunjukkan suatu ide, objek, kondisi atau situasi dan lain-lain.kegunaan data adalah sebagai bahan dasar yang objektif (relatif) di dalam pproses kebijaksanaan oleh pimpinan organisasi. (Sutabri, 2012)

Data merupakan fakta mentah tentang orang, tempat, kejadian dan apapun yang penting bagi perusahaan, dimana data itu sendiri tidak memiliki arti. Data adalah sebuah sumber yang harus dikontrol dan dikelola dan data juga adalah fakta-fakta atau observasi yang mentah, biasanya mengenai kejadian atau transaksi bisnis.(Indrajani, 2015)

\section{c. Pengertian Pengolahan Data}

Pengolahan data adalah suatu proses menerima data sebagai masukan (input) memproses (processing) menggunakan proses

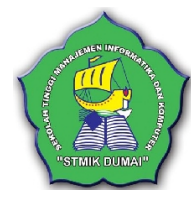

tertentu, dan mengeluarkan hasil proses data tersebut dalam bentuk informasi (output). (Mahyuni, Sharipuddin, 2014)

Suatu Proses pengolahan data terdiri atas 3 tahap dasar, yang disebut dengan siklus pengolahan data (processing cycle), yaitu input, processing dan output. (Mori Valentina, Asparizal, 2016)

\section{d. Pengertian Peserta Didik}

Peserta didik adalah orang/individu yang mendapatkan pelayanan pendidikan sesuai dengan bakat, minat, dan kemampuan agar tumbuh dan berkembang dengan baik serta mempunyai kepuasan dalam menerima pelajaran yang diberikan oleh pendidiknya. (Kirom, 2017)

\section{e. Pengertian Lembaga Kursus}

Kursus adalah suatu kegiatan pendidikan yang dilakukan dengan sengaja, terorganisir dan sistematik untuk memberikan satu mata pelajaran atau rangkaian pelajaran tertentu kepada orang dewasa atau remaja tertentu dalam waktu yang relatif singkat, agar mereka memperoleh pengetahuan, keterampilan dan sikap yang dapat dimanfaatkannya untuk mengembangkan dirinya dan masyarakatnya. (Ariz, 2012)

\section{f. Pengertian Lembaga Pelatihan}

Lembaga pelatihan merupakan satuan pendidikan nonformal, di samping satuan pendidikan lainnya seperti kursus, kelompok belajar, majelis ta'lim, kelompok bermain, taman penitipan anak, pusat kegiatan belajar masyarakat, serta satuan pendidikan yang sejenis. (Bambang Hindrajid, Anang Aris Widodo, 2016)

\section{g. Pengertian Pembelajaran}

Pembelajaran yaitu sebagai suatu upaya yang dilakukan pendidik atau guru secara sengaja dengan tujuan menyampaikan ilmu pengetahuan, dengan cara mengorganisasikan dan menciptakan suatu sistem lingkungan belajar dengan berbagai metode sehingga siswa dapat melakukan kegiatan belajar secara lebih optimal. (Kirom, 2017)

\section{h. PHP}

PHP adalah script pemrograman yang terletak dan dieksekusi di server. Salah satunya adalah untuk menerima, mengolah, dan menampilkan data dari dan ke sebuah situs. Data akan diolah ke sebuah database server 
I N F ORM A I K A

Jurnal Informatika, Manajemen dan Komputer, Vol. 11, No. 1, Mei 2019

eISSN : 2580-3042

pISSN : 1979-0694

untuk kemudian hasilnya ditampilkan di browser sebuah situs. (Madcoms, 2011)

PHP merupakan bahasa berbentuk script yang ditempatkan didalam server baru kemudian diproses. Kemudian hasil pemrosesan dikirim kepada web browser klien. Bahasa pemrograman ini dirancang khusus untuk membentuk web dinamis. Artinya, pemrograman PHP dapat membentuk suatu tampilan berdasarkan permintaaan terkini, misalnya halaman menampilkan daftar tamu. Halaman tersebut akan selalu mengalami perubahan mengikuti jumlah data tamu yang telah mengisi buku tamu. (Rubiati, 2018)

\section{i. Client-Server}

Pada Model client server, proses system terdistribusi dibagi ke dalam dua kelompok. Server merupakan proses implementasi dar sebuah layanan tertentu, contohnya sebuah layanan sistem file atau layanan basis data. Client merupakan prose meminta layanan dari server dengan cara mengirim permintaan yang kemudian menunggu balasan dari server. (Latubessy, 2014)

\section{METODOLOGI PENELITIAN}

Adapun model yang digunakan pada penelitian adalah model waterfall (siklus hidup klasik) yaitu sebagai berikut :

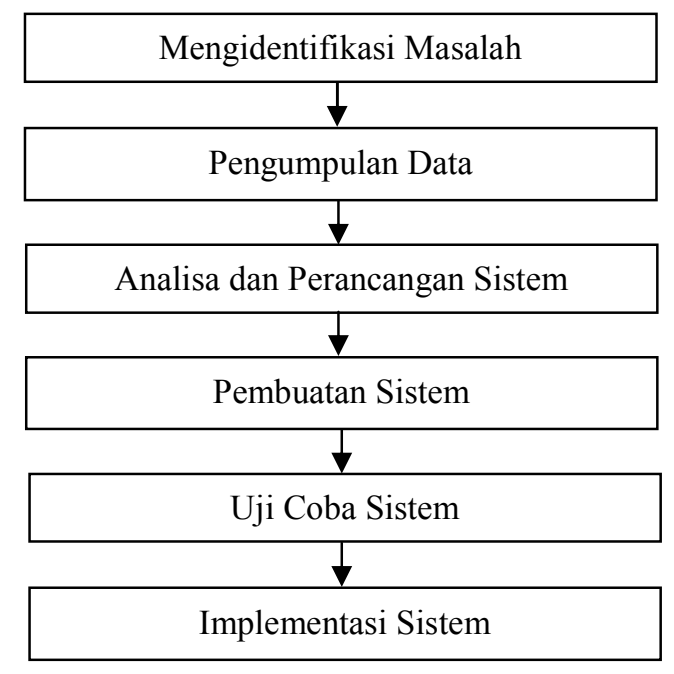

Gambar 1 Kerangka Kerja

Berikut ini penjelasan dari gambar Kerangka Kerja diatas:

1. Identifikasi Masalah

Pada tahap ini yaitu mengetahui masalahmasalah apa yang sedang dihadapi oleh tempat penelitian. Permasalahan yang dihadapi adalah proses pada LKP Prima

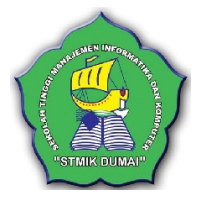

Tama Komputer Dumai di mulai dari pengolahan peserta didik hingga menghasilkan sertifikat masih dilakukan secara manual yaitu menggunakan Microsoft Excel, seperti pada pengolahan peserta didik, instruktur, program keahlian, detail program keahlian, kelas, user, pimpinan, pengajaran, absen, pengolahan nilai serta dalam mencetak sertifikat. Dan pada pembuatan laporan masih berupa arsip pembukuan. Selain itu juga kesulitan mencari data yang diperlukan jika dalam waktu yang cepat karena harus mencari satu-persatu sehingga memungkinkan waktu yang digunakan kurang efektif dan efisien.

2. Pengumpulan Data

Pada tahap ini yang dilakukan adalah pengumpulan data dengan teknik :

A. Data Primer dari pengumpulan data ini adalah :

(a) Teknik wawancara dilakukan dengan wawancara pada narasumber yaitu pimpinan LKP Prima Tama Komputer Dumai.

(b) Teknik observasi dilakukan dengan cara melakukan pengamatan langsung ke LKP Prima Tama Komputer Dumai.

B. Data Sekunder dari pengumpulan data ini adalah :

(a) Studi pustaka digunakan dari kumpulan jurnal ilmiah dan buku yang memiliki tema pembahasan yang sama dengan penelitian yang sedang dilakukan.

3. Analisa dan Perancangan Sistem

Merancang sistem pengolahan data peserta didik pada LKP Prima Tama Komputer Dumai yaitu perancangan input, output dan database yang sesuai dengan pengolahan data peserta didik. Perancangan inputnya antara lain : data peserta didik, data instruktur, data program keahlian, detail data program keahlian, data kelas, data user, data pimpinan, data pengajaran, data absen, data nilai dan data sertifikat. Perancangan outputnya yaitu laporan data peserta didik keseluruhan, perbulan, pertahun, laporan data pengajaran pertahun, laporan rekap data absen per peserta didik, laporan data nilaikeseluruhan, laporan data nilai keseluruhan, daftar nilai, laporan data sertifikat keseluruhan dan sertifikat. Perancangan filenya antara lain : file user, file peserta didik, file instruktur, file 
I N F O R M A T I A

Jurnal Informatika, Manajemen dan Komputer, Vol. 11, No. 1, Mei 2019

eISSN : 2580-3042

pISSN : 1979-0694

program keahlian, file detail program keahlian, file kelas, file pimpinan, file pengajaran, filai nilai, file detail nilai dan file sertifikat.

4. Pembuatan Sistem

Pembuatan sistem berdasarkann perancangan sistem dengan menggunakan Bahasa pemrograman PHP.

5. Uji Coba Sistem

Pada tahap ini, hasil penerapan sistem pengolahan data peserta didik hingga menghasilkan sertifikat dengan menggunakan Microsoft Excel dengan penerapan sistem pengolahan data peserta didik hingga menghasilkan sertifikat dengan menggunakan Bahasa pemrograman PHP, dengan tujuan untuk mengetahui apakah sistem telah berjalan sesuai yang diinginkan.

6. Implementasi Sistem

Pada tahap ini dilakukan pengimplementasian sistem pada LKP Prima Tama Komputer Dumai.

3. HASIL DAN PEMBAHASAN

a. Aliran Sitem Informasi Yang Sedang Berjalan.

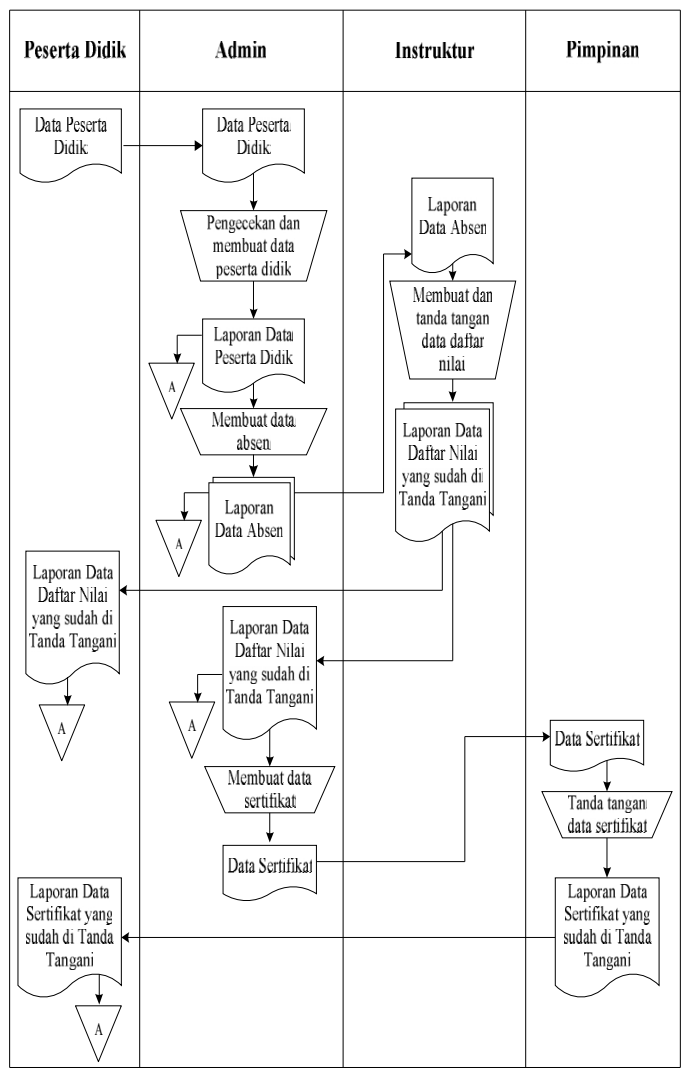

Gambar 2 Aliran Sistem Informasi yang sedang berjalan

Adapun keterangan Aliran Sistem Informasi yang sedang berjalan adalah sebagai berikut :

1. Peserta didik menyerahkan data peserta didik kepada admin.

2. Admin memeriksa data peserta didik dari data peserta didik.

3. Setelah diperiksa admin membuat data absen sebanyak 2 rangkap. 1 rangkap diserahkan kepada instruktur, kemudian 1 rangkap untuk diarsipkan.

4. Instruktur membuat dan menandatangani data daftar nilai sebanyak 2 rangkap. 1 rangkap diserahkan kepada admin, kemudian 1 rangkap diserahkan kepada peserta didik untuk diarsipkan.

5. Admin membuat data sertifikat yang diserahkan kepada pimpinan untuk ditandatangani.

6. Data sertifikat yang sudah ditandatangani diserahkan kepada peserta didik untuk diarsipkan.

b. Aliran Sistem Informasi yang baru Adapun keterangan Aliran Sistem Informasi yang baru adalah sebagai berikut :

1. Peserta didik menyerahkan data peserta didik kepada admin.

2. Admin menginputkan data peserta didik ke sistem dan tersimpan ke database. Data peserta didik yang telah diinputkan menghasilkan laporan data peserta didik sebanyak 2 rangkap untuk ditandatangani oleh pimpinan. 1 rangkap diarsipkan oleh admin dan 1 rangkap diserahkan kepada pimpinan untuk diarsipkan.

3. Admin menginputkan data pengajaran ke sistem dan tersimpan ke database. Data pengajaran yang telah diinputkan menghasilkan laporan data pengajaran. Laporan data pengajaran ditandatangani oleh pimpinan, kemudian diarsipkan oleh admin.

4. Instruktur menginputkan data absen ke sistem dan tersimpan ke database. Data absen yang telah diinputkan menghasilkan laporan rekap data absen sebanyak 2 rangkap untuk ditandatangani oleh pimpinan. 1 rangkap diarsipkan oleh admin dan 1 rangkap diserahkan kepada pimpinan untuk diarsipkan.

5. Instruktur menginputkan data nilai ke sistem dan tersimpan ke database. Data nilai yang telah diinputkan menghasilkan laporan data nilai dan laporan daftar nilai. Laporan data nilai ditandatangani oleh pimpinan, kemudian diarsipkan oleh 
I N F ORM A I K A

Jurnal Informatika, Manajemen dan Komputer, Vol. 11, No. 1, Mei 2019

eISSN : 2580-3042

pISSN : 1979-0694

admin. Laporan daftar nilai ditandatangani oleh instruktur, kemudian diserahkan kepada peserta didik untuk diarsipkan.

6. Admin menginputkan data sertifikat ke sistem dan tersimpan ke database. Data sertifikat yang telah diinputkan menghasilkan laporan data sertifikat dan sertifikat yang ditandatangani oleh pimpinan. Laporan data sertifikat yang telah ditandatangani diarsipkan oleh admin, sedangkan sertifikat diserahkan kepada peserta didik untuk diarsipkan.

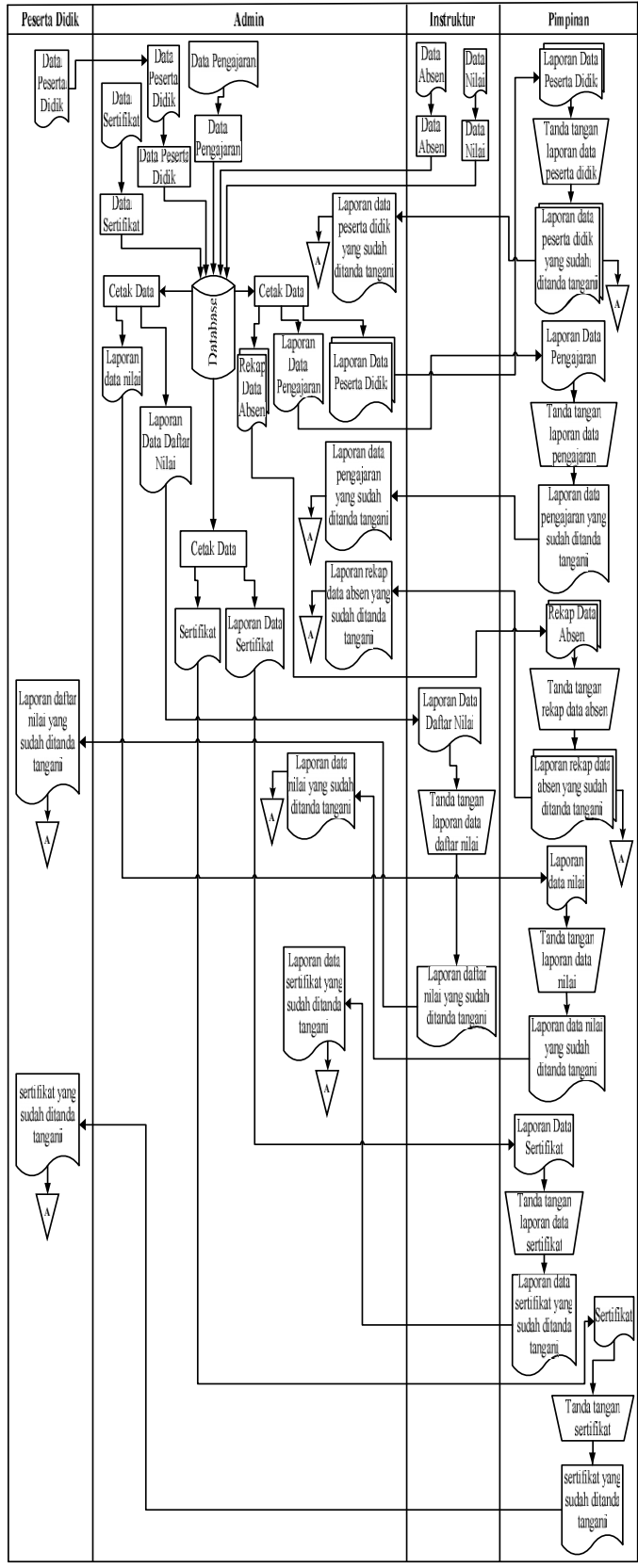

Gambar 3 Aliran Sistem Informasi yang baru

\section{c. Context Diagram}

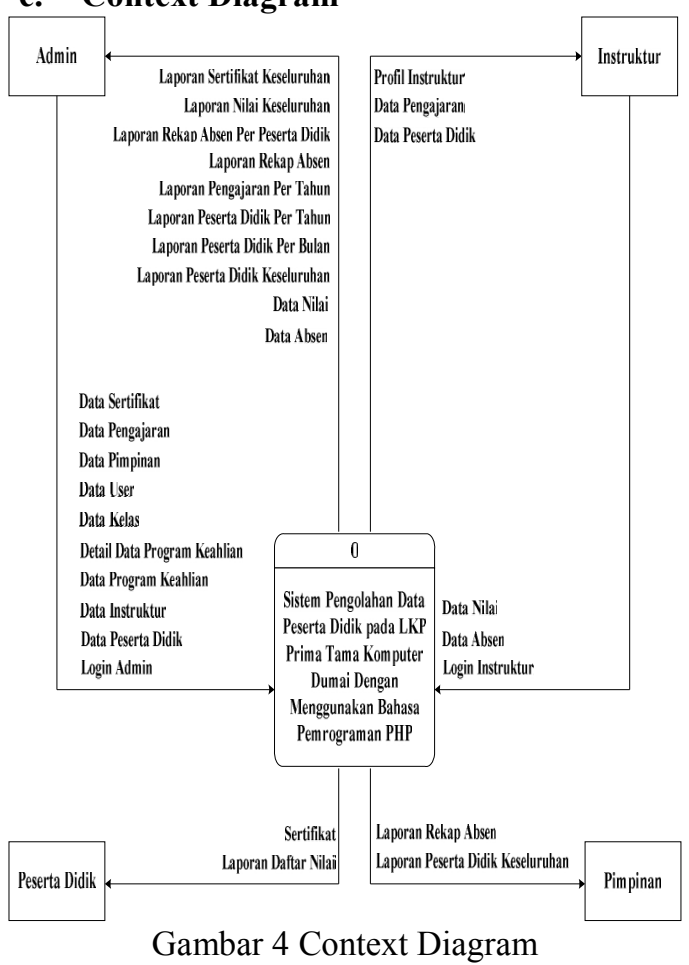

d. Tampilan Program

1. Halaman Beranda

Pada halaman beranda ini terdapat halaman login serta dapat melihat foto-foto kegiatan LKP Prima Tama Komputer Dumai.

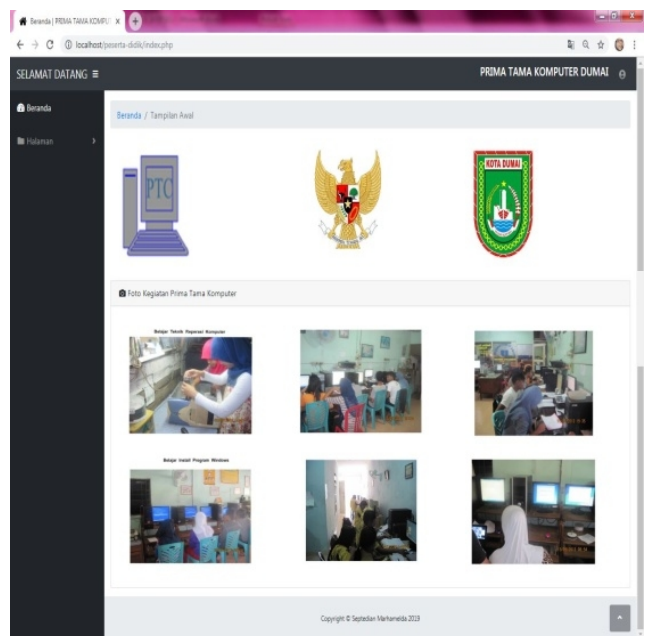

Gambar 5 Halaman Beranda

2. Halaman Login

Pada tampilan login sistem terdapat dua akses untuk user, yaitu hak akses sebagai admin dan instruktur.

a) Pilihan ini adalah akses untuk melakukan login bagi Admin. Di bawah ini adalah gambar form login Admin : 
I N F ORM A I K A

Jurnal Informatika, Manajemen dan Komputer, Vol. 11, No. 1, Mei 2019

eISSN : 2580-3042

pISSN : 1979-0694

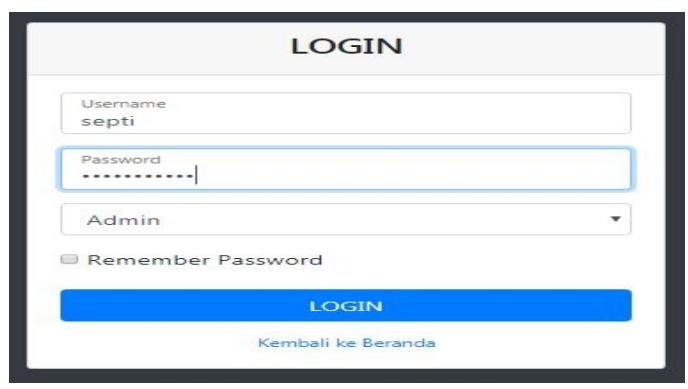

Gambar 6 Tampilan Form Login Admin

b) Pilihan ini adalah akses untuk melakukan login bagi Instruktur. Di bawah ini adalah gambar form login Instruktur :

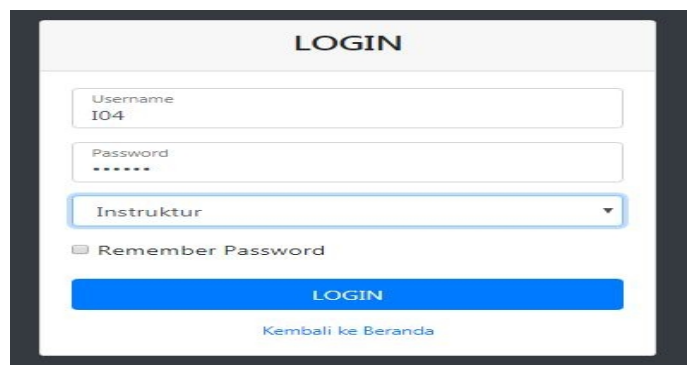

Gambar 7 Tampilan Form Login Instruktur

3. Tampilan Menu Utama

a) Adapun tampilan menu utama untuk admin seperti gambar di bawah ini :

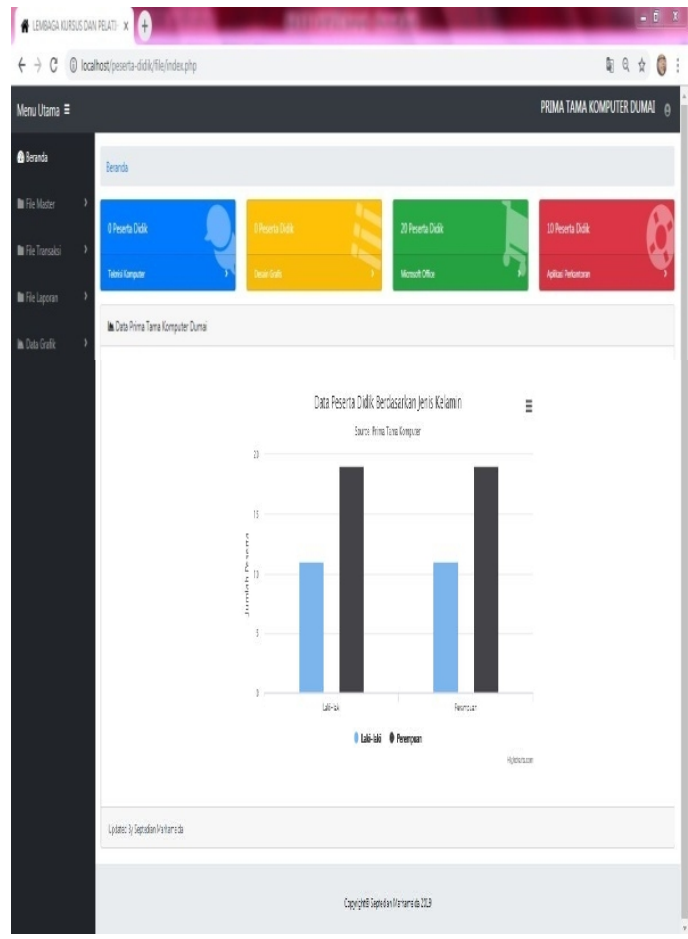

Gambar 8 Tampilan Menu Utama Admin

b) Adapun tampilan menu utama untuk instruktur seperti gambar di bawah ini :

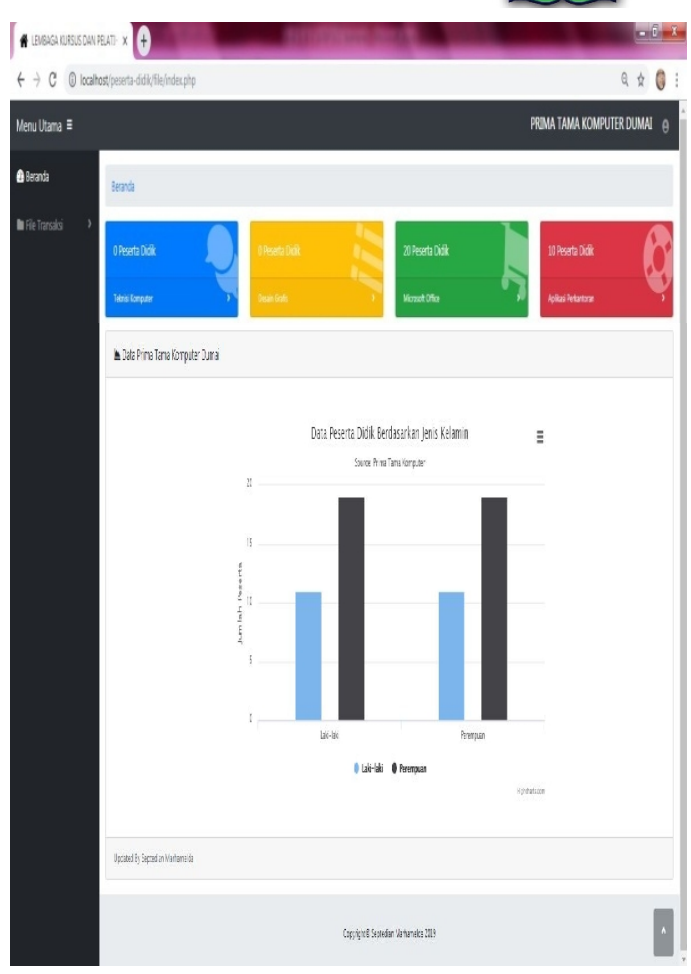

Gambar 9 Tampilan Menu Utama Instruktur

4. Tampilan Menu Input Pada Data Master a) Data Peserta Didik

Adapun tampilan input data peserta didik adalah sebagai berikut :

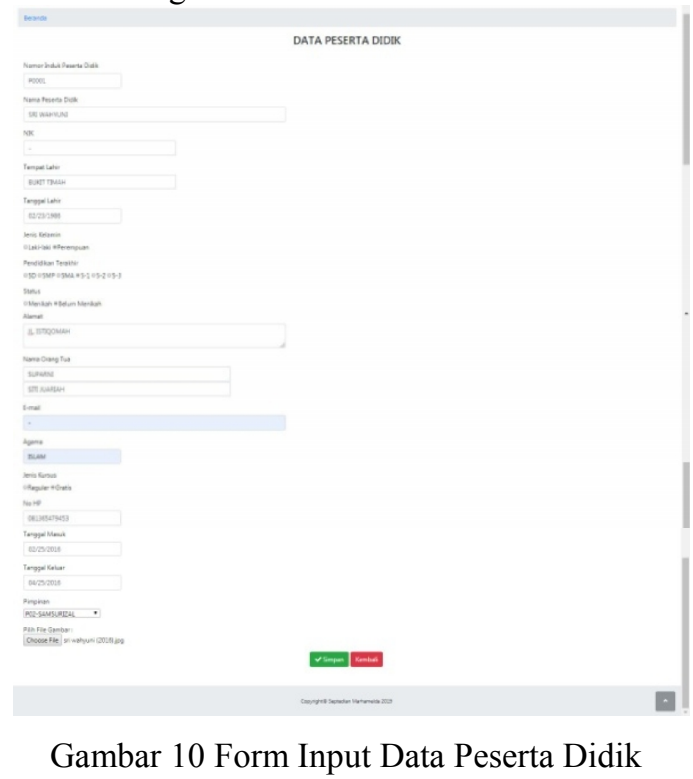

b) Data Instruktur

Adapun tampilan input data instruktur adalah sebagai berikut : 
I N F ORM A I K A

Jurnal Informatika, Manajemen dan Komputer, Vol. 11, No. 1, Mei 2019

eISSN : 2580-3042

pISSN : 1979-0694

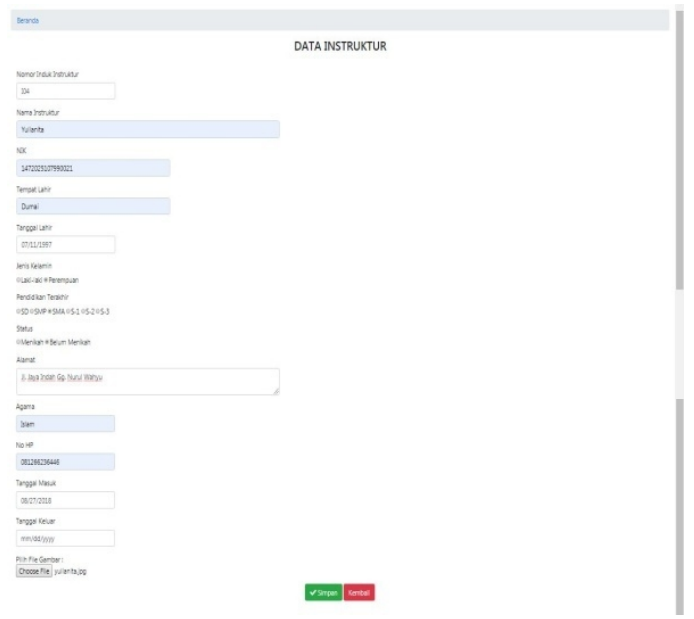

e) Data User

Adapun tampilan input data user adalah sebagai berikut :

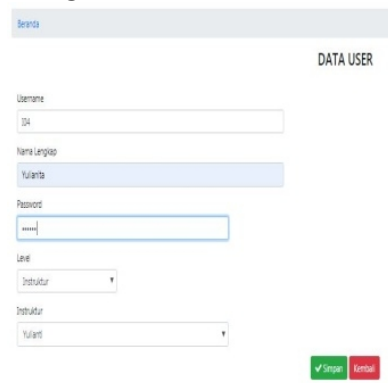

Gambar 15 Form Input Data User

Gambar 11 Form Input Data Peserta Didik

c) Data Program Keahlian

Adapun tampilan input data program keahlian adalah sebagai berikut :

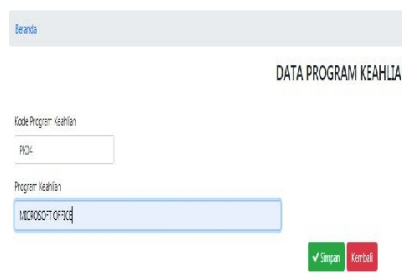

Gambar 12 Form Input Data Program Keahlian

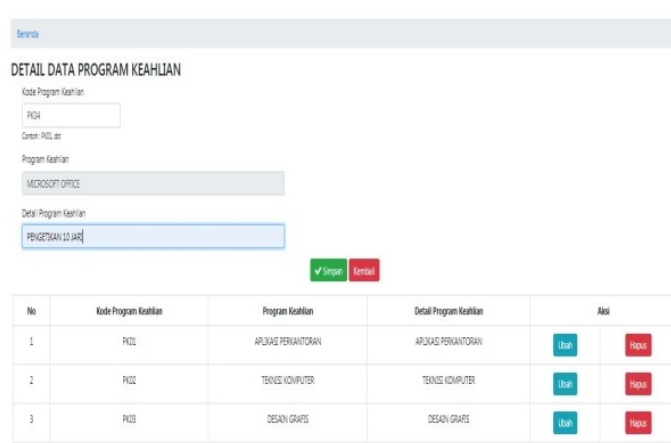

Gambar 13 Form Input Data Detail Program Keahlian

d) Data Kelas

Adapun tampilan input data kelas adalah sebagai berikut :

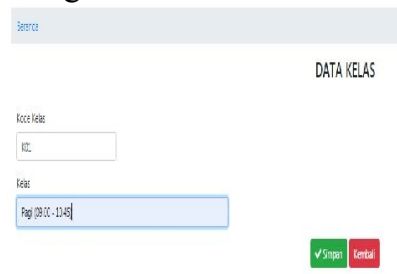

Gambar 14 Form Input Data Kelas

f) Data Pimpinan

Adapun tampilan input data pimpinan adalah sebagai berikut :

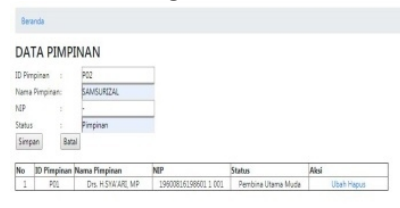

Gambar 16 Form Input Data Pimpinan

5. Tampilan Laporan

a) Laporan Data Peserta Didik

Adapun tampilan laporan data peserta didik adalah sebagai berikut :

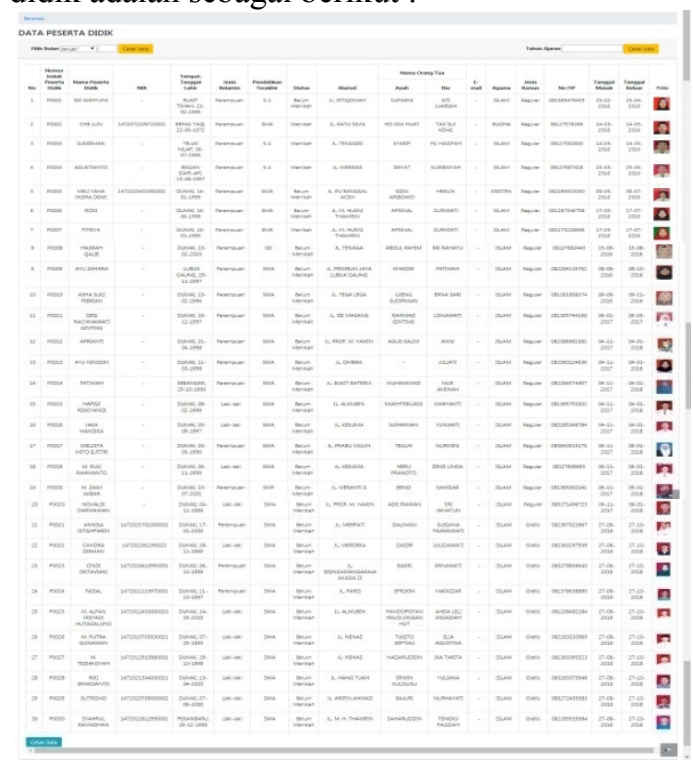

Gambar 17 Form Laporan Data Peserta Didik

b) Laporan Data Pengajaran

Adapun tampilan laporan data pengajaran adalah sebagai berikut : 
I N F ORM A I K A

Jurnal Informatika, Manajemen dan Komputer, Vol. 11, No. 1, Mei 2019

eISSN : 2580-3042

pISSN : 1979-0694

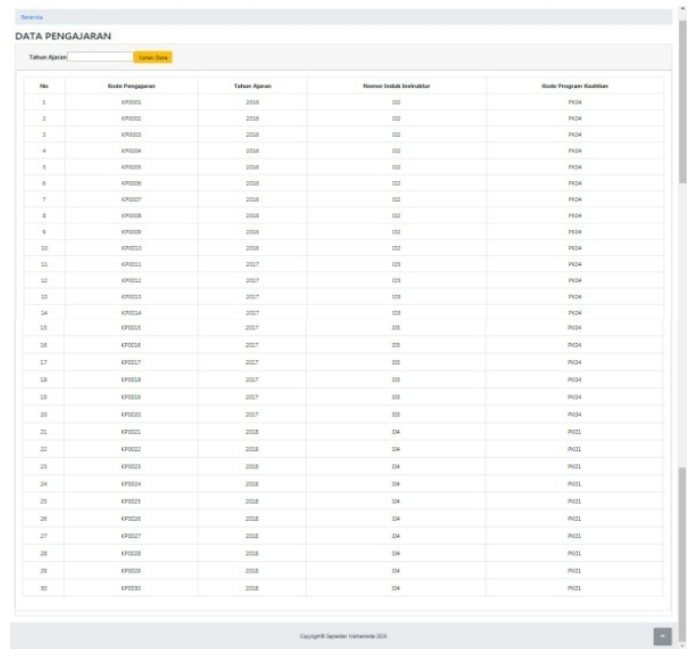

Gambar 18 Form Laporan Data Pengajaran

c) Laporan Data Absen

Adapun tampilan laporan data absen adalah sebagai berikut :

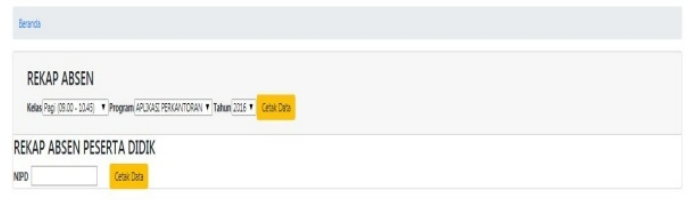

Gambar 19 Form Laporan Data Absen

d) Laporan Data Nilai

Adapun tampilan laporan data nilai adalah sebagai berikut :

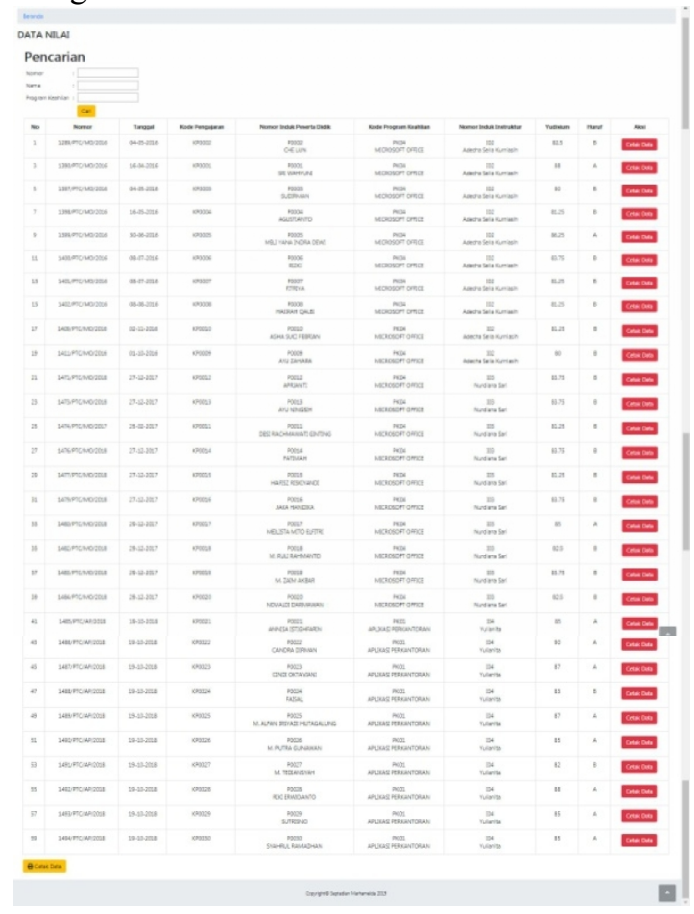

Gambar 20 Form Laporan Data Nilai

e) Laporan Data Sertifikat

Adapun tampilan laporan data sertifikat adalah sebagai berikut :

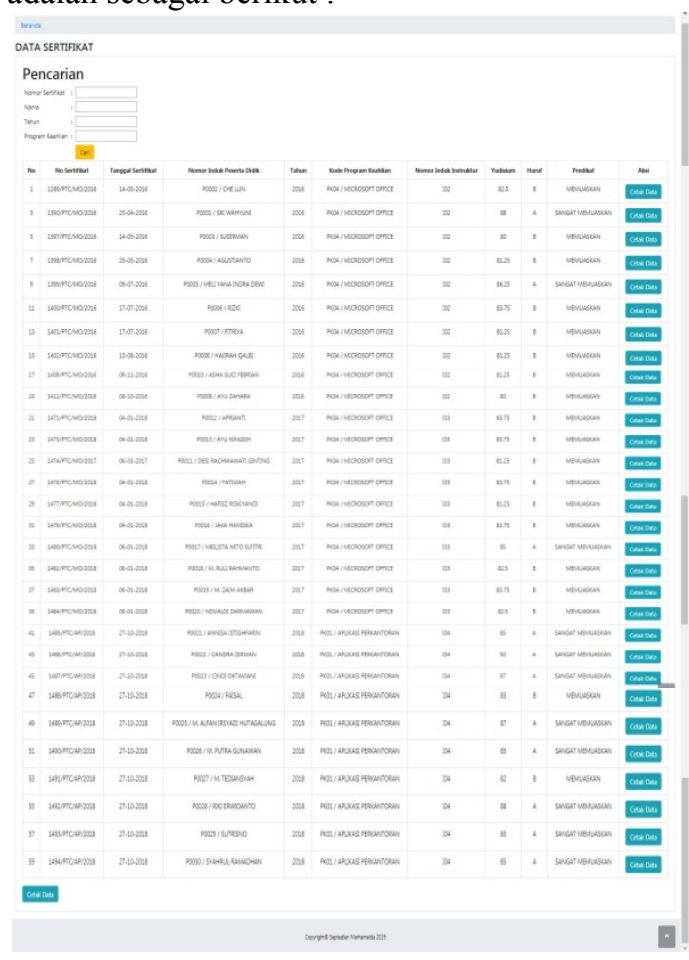

Gambar 21 Form Laporan Data Sertifikat

\section{KESIMPULAN}

Berdasarkan hasil pembahasan yang telah diuraikan, dapat diambil kesimpulan sebagai berikut :

1) Tidak ada redudansi data dalam pengolahan data peserta didik. Hal ini dibuktikan dengan, apabila primery key yang sama diinput maka data tidak bisa disimpan.

2) Data peserta didik pada LKP Prima Tama Komputer Dumai mudah dicari, dibuktikan dengan adanya form pencarian.

3) Mudah membuat data. Hal ini dibuktikan dengan laporan akan otomatis diperloh apabila data master dan data transaksi sudah diinput.

\section{REFERENSI}

Ariz, D. (2012). Evaluasi Hasil Belajar Keterampilan Komputer Berbasis Kompetensi (Studi Kasus Kursus Komputer Program Aplikasi Dasar Di Lembaga Pendidikan Kursus Kharisma College Kecamatan Ciranjang Kabupaten Cianjur). Jurnal Empowerment, 1(2), 130-140. Retrieved from http://ejournal.stkipsiliwangi.ac.id/index.php/em powerment/article/view/623 
I N F ORM T I K A

Jurnal Informatika, Manajemen dan Komputer, Vol. 11, No. 1, Mei 2019

eISSN : 2580-3042

pISSN : 1979-0694

AS, Rosa, and M. Shalahuddin. 2011. Rekayasa Perangkat Lunak (Terstruktur Dan Berorientasi Objek). Bandung: Modula.

Bambang Hindrajid, Anang Aris Widodo, A. P. N. (2016). Enterprise Sistem Administrasi Untuk Lembaga Kursus Dan Pelatihan Studi Kasus Di Lkp Inka Group Pasuruan. Jurnal Informatika Merdeka Pasuruan, 2(1), 81-110. Retrieved from http://ejurnal.unmerpas.ac.id/index.php/in formatika/article/view/25

Indrajani. (2015). Database Design (Case Study All in One). Jakarta: PT. Elex Media Komputindo.

Jogiyanto. (2005). Analisis Dan Desain (3rd ed.). Yogyakarta: C.V ANDI OFFSET (Penerbit ANDI).

Kirom, A. (2017). Peran Guru Dan Peserta Didik Dalam Proses Pembelajaran Berbasis Multikultural. Jurnal Pendidikan Agama Islam, 3(1), 69-80. Retrieved from

http://jurnal.yudharta.ac.id/v2/index.php/p ai/article/view/893

Latubessy, A. (2014). Analisa Dan Perancangan Sistem Pemasaran Umkm Terintegrasi Berbasis Cloud Server. Jurnal SIMETRIS, 5(1), 1-10. Retrieved from https://jurnal.umk.ac.id/index.php/simet/a rticle/view/133/139

Madcoms. (2011). Aplikasi Web Database dengan Dreamweaver dan PHP-MySQL. Yogyakarta: CV. Andi Offset.

Mahyuni, Sharipuddin, M. (2014). Perancangan Sistem Pengolahan Data Pada Sma Negeri 6 Kabupaten Tebo. Jurnal Ilmiah Media SISFO, 8(3), 180-187. Retrieved from http://ejournal.stikom-

db.ac.id/index.php/mediasisfo/article/view $/ 158 / 153$

Mori Valentina, Asparizal, T. R. (2016). Sistem Pengolahan Data Klien Dan Dokumen Pada Irna Rocha, Sh Menggunakan Visual Basic.Net. Jurnal Informatika, Manajemen Dan Komputer, 8(2), 37-42. Retrieved from http://ejournal.stmikdumai.ac.id/index.ph $\mathrm{p} /$ path/article/view/127

Rubiati, N. (2018). Aplikasi Informasi Pelayanan Fitness Pada Golden Fitness Center Dumai Dengan Bahasa Pemrograman Php. Jurnal Informatika, 